\begin{tabular}{|c|l|}
\hline Title & The Role of Vole Populations in Prevalence of the Parasite (Echinococcus multilocularis) in Foxes \\
\hline Author(s) & SAITOH, Takashi; TA KA HA SHI, Kenichi \\
\hline Citation & Researches on population ecology, 40(1), 97-105 \\
\hline Issue Date & 1998 \\
\hline Doc URL & http://hdl.handle.net/2115/17002 \\
\hline Type & article \\
\hline File Information & RPE40-1-97.pdf \\
\hline
\end{tabular}

Instructions for use 


\title{
The Role of Vole Populations in Prevalence of the Parasite (Echinococcus multilocularis) in Foxes
}

\author{
Takashi SAITOH ${ }^{1)}$ and Kenichi TAKAHASHI ${ }^{2)}$ \\ 1) Hokkaido Research Center, Forestry and Forest Products Research Institute, Sapporo 062-8516, Japan \\ 2) Hokkiado Institute of Public Health, Kita 19, Nishi 12, Sapporo 060-0819, Japan
}

\begin{abstract}
Effects of population fluctuation of the gray-sided vole (Clethrionomys rufocanus) on the prevalence (infection rates) of the parasite Echinococcus multilocularis in red fox (Vulpes vulpes) populations was investigated from 1985 to 1992 in eastern Hokkaido (Abashiri, Nemuro, and Kushiro area), Japan. This parasite needs two hosts to complete its life cycle; the gray-sided vole as its intermediate host and the red fox as its final host. We found that: (1) Infection rates in foxes depended on the current-year abundance of voles in all three study areas, particularly in Abashiri. (2) In addition to this direct density-dependence, delayed density-dependence between the infection rate and the prior-year abundance of voles was detected in Nemuro and in Kushiro. (3) The regional differences in density-dependence pattern were related to regional differences in the winter food habits of red foxes: in Abashiri the proportion of voles in the fox's diet greatly decreases in winter, while the proportion remains high in winter in Nemuro and in Kushiro, probably because of shallower snowpack. These results suggest that infection rates in foxes in Abashiri were less influenced by the prior-year prevalence, since the infection cycle might be interrupted in winter, when voles became less important in fox's diet. In contrast, the state of the prevalence may carry over from year to year in Nemuro and in Kushiro, because red foxes continue to eat a considerable amount of voles throughout year. The regionally contrasted results for the relationship between infection rate in foxes and vole abundance were parallel to the regional difference in fluctuation pattern of vole populations, which are highly variable in Abashiri area, but less variable in Kushiro-Nemuro area. Drastic change in vole populations appears to affect the host-parasite system.
\end{abstract}

Key words: Clethrionomys rufocanus, density-dependence, functional response, numerical response, Vulpes vulpes.

\section{Introduction}

The vole Clethrionomys rufocanus (Sundevall, 1846) is the most common small mammals in Hokkaido, Japan (Ota 1984; Henttonen et al. 1992; Kaneko et al. 1998). Its populations greatly fluctuate with periodic or aperiodic pattern (Bjørnstad et al. 1996, 1998; Stenseth et al. 1996; Saitoh et al. 1998b). Many carnivorous species depend on this vole. For instance, even the red fox (Vulpes vulpes (L.)), which is a typical generalist predator (Lloyd 1980), selectively takes this vole like a specialist predator in Hokkaido (Yoneda 1979). In Fennoscandia, populations of foxes track vole populations (Hörnfeldt et al. 1986; Lindén

1)E-mail: bedford@ffpri-hkd.affrc.go.jp

2)E-mail: takaken@iph.pref.hokkaido.jp
1988; Lindström 1989; Small et al. 1993) and reproduction and feeding pattern of predatory species are also greatly influenced by the population fluctuation of voles (Korpimäki and Norrdahl 1991; Korpimäki et al. 1991; Korpimäki 1994; Lindström 1992, 1994). Thus the most common voles could be the keystone species that essentially influences the predator-prey system, and also could be essential for the host-parasite system with parasites that alternate hosts to complete their life cycle in wildlife. Populations of such parasites may respond to host densities through interactions between intermediate (a prey species) and final (a predator species) hosts (e.g. Haukisalmi and Henttonen 1994), which in turn may both be affected by the parasites.

Echinococcus multilocularis Leuckart is a taeniid cestode; voles are its intermediate host and foxes, which prey 
on voles, are its final host (Fig. 1). The disease caused by E. multilocularis, alveolar echinococcosis, is a serious zoonosis in central Europe, North America and east Asia (Schantz et al. 1995). In Japan this disease had been restricted to an islet, Rebun (Fig. 2). In 1965, however, the first human case was reported on the main island of Hokkaido. Since then the disease has been spreading all over the island, being particularly serious in eastern regions of the main island.

In Hokkaido E. multilocularis maintains its life cycle mainly in two hosts, the gray-sided vole (Clethrionomys rufocanus) and the red fox (Vulpes vulpes) (Ohbayashi 1996). Here, we report yearly changes in infection rates of the parasite ( $E$. multilocularis) in red fox populations and analyze effects of fluctuating abundance of gray-sided voles on the infection rates in three eastern regions of Hokkaido.

\section{Materials and methods}

\section{Study area}

Hokkaido is the northernmost island $\left(41^{\circ} 24^{\prime}-45^{\circ} 31^{\prime} \mathrm{N}\right.$, $139^{\circ} 50^{\prime}-145^{\circ} 49^{\prime} \mathrm{E}$ ) of Japan, covers $78,073 \mathrm{~km}^{2}$, and is divided into 14 administrative districts. Alveolar echinococcosis was restricted to Rebun islet for about 30 years in Japan, since the first human case was reported in 1937. However, the disease was found in the main island of Hokkaido (Nemuro city) in 1965, and has since spread all over the main island from the core of the eastern regions (Fig. 2). As of 1994, 213 human cases had been reported from the main island. Of 152 patients found between 1965 and $1989,85.5 \%$ are from the eastern regions (Suzuki et al. 1993). In contrast, this disease has recently been eradicated from Rebun islet, by controlling its final hosts. We focused on three eastern districts (Abashiri, Nemuro, and Kushiro), because the parasite may have established itself for sufficient length of time to be analyzed (Takahashi in preparation).

The studied three districts covers about 26\% (20,183 $\mathrm{km}^{2}$ ) of the island's total area (Fig. 2). Northeast coasts (Ohmu town, Mombetsu town, and Abashiri city in Abashiri district) have more snow than southeast coasts (Nemuro and Kushiro city), although there are no distinct deviations in temperatures (Table 1).

The gray-sided vole is the most common small mammal in Hokkaido. It is abundant in forests as well as in open fields, probably because of the absence of Microtus in Hokkaido (Ota 1984). The main predators are the least weasel (Mustela nivalis L.) and the red fox, although the predator community is rich in Hokkaido, but has fewer nomadic predators (Henttonen et al. 1992). A rich alternative prey community (hares, grouse, and frogs) also

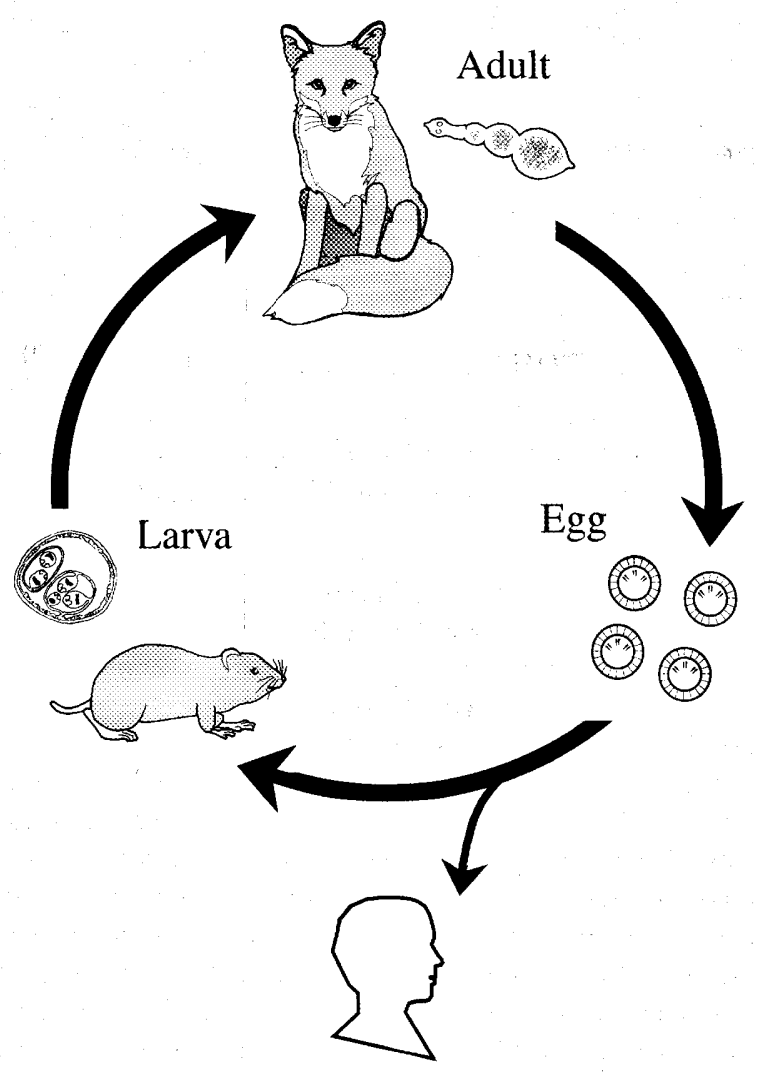

Fig. 1. Life cycle of Echinococcus multilocularis. This parasite maintains its life cycle mainly in two hosts, the intermediate host, the gray-sided vole (Clethrionomys rufocanus), and the final host, the red fox (Vulpes vulpes) in Hokkaido. When a human accidentally ingests its eggs, the alveolar echinococcosis sometimes causes a serious disease of liver.

characterizes Hokkaido like southern Fennoscandia.

\section{Fox infection rate}

During 1985-1992 the Hokkaido government collected 9,828 red foxes, which were hunted in winter (from November to March) all over the island, to monitor infection rates of E. multilocularis. The total sample sizes and its range (in parentheses) for the eight years in the three districts were as follows: $1,159(110-180)$ for Abashiri; 966 (80-146) for Nemuro; 845 (48-189) for Kushiro. Veterinarians and/or specialists inspected a part of the small intestine (the last $30 \mathrm{~cm}$ ) of each red fox with a stereoscopic microscope in a special room for the necropsy.

\section{Vole census}

Since 1954 the Hokkaido government has carried out a incentive program for private foresters to census voles for 


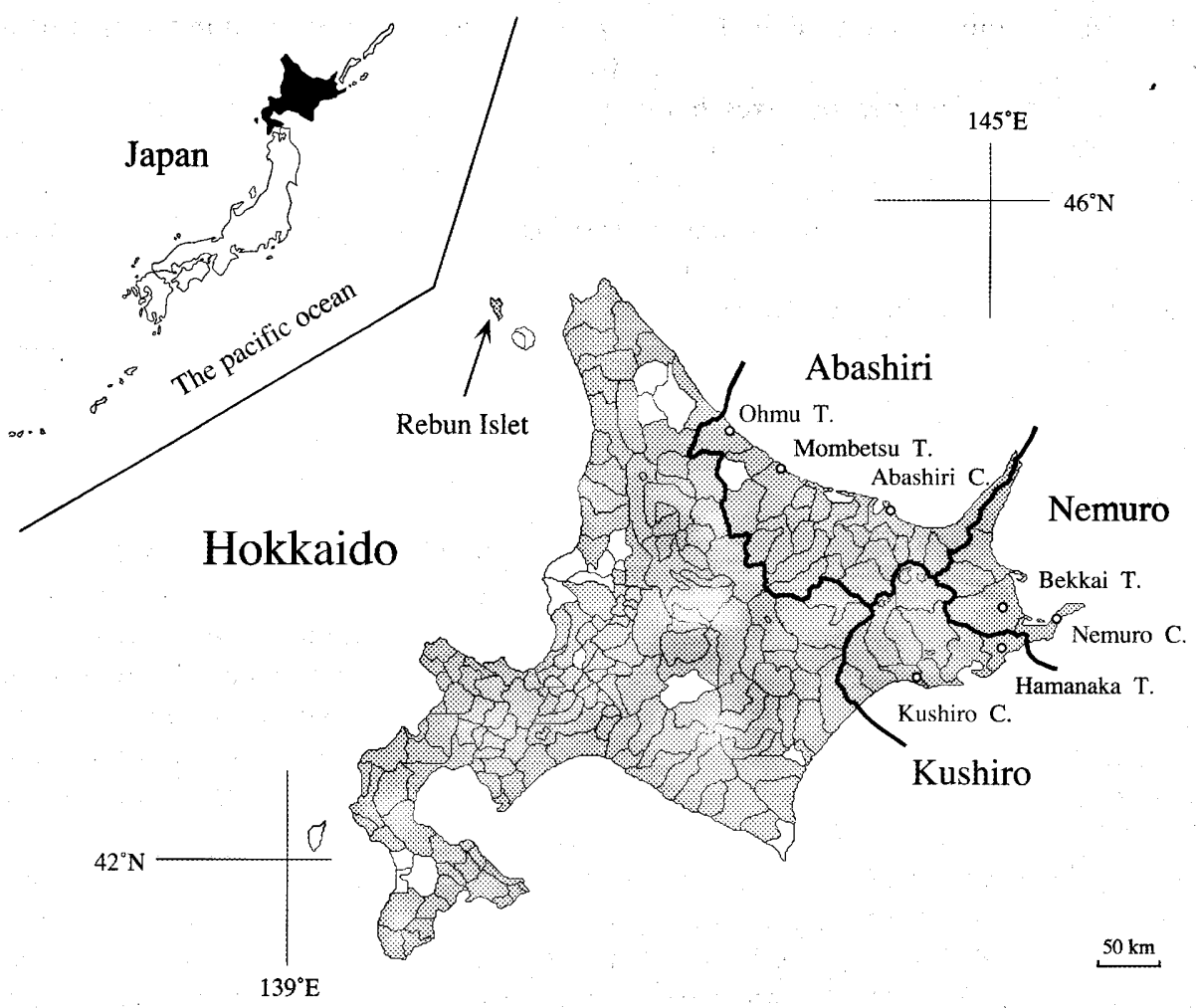

Fig. 2. Map of the study area. Shaded areas indicate cities/towns, where $E$. multilocularis has been found by 1992 . The three districts studied shown by thick lines.

pest management (Kaneko et al. 1998). Since the same year the Forestry Agency of the Japanese government has also carried out similar censuses in national forests all over Hokkaido (see Saitoh et al. 1997, 1998b for details of census methods). Of these two potential sources of data, we used the census data from private natural forests investigated by designated, trained specialists, because most private forests are near suburban or cultivated areas, and therefore offer suitable habitats for red foxes. In contrast most national forests are located in mountainous areas (Kaneko et al. 1998). The trappings were carried out at 18 sites in Abashiri, at three sites in Nemuro, and at nine sites in Kushiro. The averaged values of fall census (150 trap nights; 50 traps for three nights in September/October) were used as indexes of vole abundance, which are good indicators of yearly population levels because vole popu-

Table 1. Meteorological data for principal towns/cities in eastern Hokkaido (see Fig. 2). Values of temperatures are given as monthly averages during 1985-1992 in each category. The lowest and highest temperatures in a year usually occur in January and August, respectively. The total precipitation $(\mathrm{mm})$, the maximum snow depth $(\mathrm{cm})$, and the number of days with snow cover over $10 \mathrm{~cm}$ in a year are also given as averages during 1985-1992 (source: Sapporo District Meteorological Office 1991, 1992).

\begin{tabular}{|c|c|c|c|c|c|c|}
\hline \multirow{2}{*}{$\begin{array}{l}\text { City } \\
\text { (or Town) }\end{array}$} & \multicolumn{3}{|c|}{ Temperature $\left({ }^{\circ} \mathrm{C}\right)$} & \multicolumn{3}{|c|}{ Precipitation } \\
\hline & January & August & Average & $\begin{array}{c}\text { total } \\
\text { annual } \\
(\mathrm{mm})\end{array}$ & $\begin{array}{l}\text { snow } \\
\text { depth } \\
(\mathrm{cm})\end{array}$ & $\begin{array}{c}\text { snow } \\
\text { days } \\
(\geqq 10 \mathrm{~cm})\end{array}$ \\
\hline Ohmu & -7.0 & 18.7 & 5.4 & 888 & 62.9 & 113.0 \\
\hline Mombetsu & -6.2 & 19.4 & 6.2 & 838 & 53.8 & 101.6 \\
\hline Abashiri & -6.1 & 19.6 & 6.4 & 794 & 49.6 & 100.8 \\
\hline Kushiro & -6.0 & 18.0 & 5.9 & 1,003 & 35.3 & 43.4 \\
\hline Nemuro & -4.2 & 17.3 & 6.1 & 1,059 & 32.8 & 37.1 \\
\hline
\end{tabular}


lations usually reach their maximum abundance in fall (Saitoh 1987; Saitoh et al. 1998a).

Even though most data on infection rates in foxes in Nemuro district came from foxes hunted in Nemuro city $(70.2 \%)$, the three vole trapping sites in this district did not include Nemuro city. Thus, we used the fall census data on voles in national forests, instead of the data in private forests. As the national forests include Nemuro city, Bekkai town, and Hamanaka town, we compared infection rates in foxes in these city or towns with the census data on voles.

\section{Assumptions and regression analyses}

In Hokkaido E. multilocularis maintains its life cycle mainly in two hosts, the gray-sided vole and the red fox (Ohbayashi 1996). Although other rodents (C. rutilus (Pallas), C. rex Imaizumi, Apodemus argenteus (Temminck), Mus musculus L., Rattus norvegicus (Berkenhout)), can be intermediate hosts and the raccoon dog, Nyctereutes procyonoides (Gray), can be a final host in the wild, their roles are minor in the infection cycle of natural populations, because of their small population sizes and/or low infection rates (Ohbayashi 1996). The transmission cycle comprises three stages (Fig. 1). An infected fox sheds feces with $E$. multilocularis eggs. The eggs are ingested by a gray-sided vole and hatch in its stomach. The oncospheres penetrate mucosa in the small intestine and transfer through the blood stream to the liver, where they develop asexually into metacestodes and increase in number. The infected vole is eaten by a fox, and the parasite completes its sexual development between villi of the small intestine in the fox, leading to egg formation. This infection cycle may be completed several times a year.

An infected fox begins to shed feces with eggs four to five weeks after infection; the number of eggs in feces increases rapidly and then gradually decreases (Yagi et al. 1996). Since no eggs were detected in fox feces three months post-infection (Yagi and Ito 1994), adult parasites may leave the fox several months after infection. Eggs excreted by the fox are small and oval $(30$ micrometer in diameter), notably resistant to adverse environmental conditions. Eggs do not lose the infectivity to intermediate hosts for more than 200 days in some laboratory and field environments (Ishige et al. 1993; Veit et al. 1995).

Density-dependent interactions are expected between the intermediate (prey) and the final host (predator). Predators immediately (functionally) respond to prey densities by switching their prey species, whereas predators specialized to a prey species are expected to exhibit delayed numerical response to prey densities (see for wildlife examples; Korpimäki and Norrdahl 1991; Korpimäki et al. 1991; Korpimäki 1993; Rohner 1997). These relationships may affect the transmission cycle. The infection rate for foxes $\left(r_{t}\right)$ depends on the number of infected voles that a fox eats. The number of infected voles taken by a fox is determined by the infection rate in voles $\left(q_{t}\right)$ and the amount of voles in a fox's diet $\left(V_{t}\right.$; Fig. 3a). The infection rate in voles depends on the amount of eggs in the environment, which is determined by the number of infected foxes $\left(P_{t} \cdot r_{t} ;\right.$ Fig. 3b). The amount of voles in a fox's diet $\left(V_{t}\right)$ depends on the vole abundance $\left(N_{t}\right)$, if the predation of foxes functionally responds to vole abundance (Fig. 3c). If fox specialized to the vole, delayed numerical response is expected; i.e. fox populations $\left(P_{t}\right)$ track vole populations with lag (Fig. 3d). Although the infection rate in voles $\left(q_{t}\right)$, the amount of voles in a fox's diet $\left(V_{t}\right)$ and the fox abundance $\left(P_{t}\right)$ are unknown in this study, these three parameters may be a function of the vole abundance $\left(N_{t}\right)$. Thus some relationship between the infection rate in foxes $\left(r_{t}\right)$ and the vole abundance $\left(N_{t}\right)$ could be expected. Furthermore, a delayed effect may emerge from the interactive relationship between predator and prey, since the infection cycle may be completed several times during a year.

The infection in foxes was examined in winter. Since adult parasites leave the fox several months after infection (Yagi and Ito 1994), foxes having the parasite in winter are probably infected in fall-winter. We could, therefore, expect some relationship between the infection rate in foxes in winter and the autumn abundance of voles. If we also assume delayed effects in the
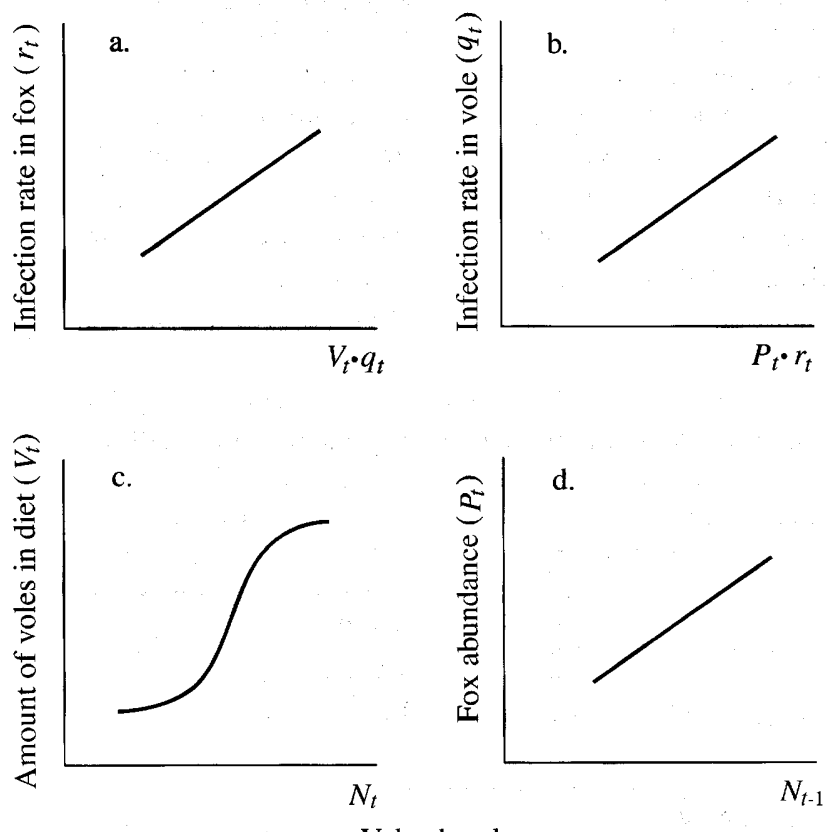

Vole abundance

Fig. 3. Schematic explanation for expected relationships among the infection rate in foxes $\left(r_{t}\right)$, the infection rate in voles $\left(q_{t}\right)$, the amount of voles in a fox's diet $\left(V_{t}\right)$, and the fox abundance $\left(P_{t}\right)$. Relationships are indicated by a tentative line (or curve). 
interactive relationship between foxes and voles, the infection rate in foxes may be associated with the fall abundance of voles in the current and the previous year, and the prior infection rate in foxes. We analyzed this relationship using the logistic regression (SAS, The GENMOD Procedure and SPSS for Macintosh release 6.1); the vole abundance and the prior infection rate were transformed into the natural logarithmic form and the logit form, respectively.

The permutation test for two independent samples was used for comparison of the infection rates and vole abundance between regions (Siegel and Castellan 1988).

\section{Results}

\section{Infection rate in foxes}

The infection rates of $E$. multilocularis in foxes greatly fluctuated during 1985-1992, and the fluctuation patterns were similar in Abashiri and in Kushiro (Fig. 4a, c). The highest peaks occurred in 1986 in these districts and

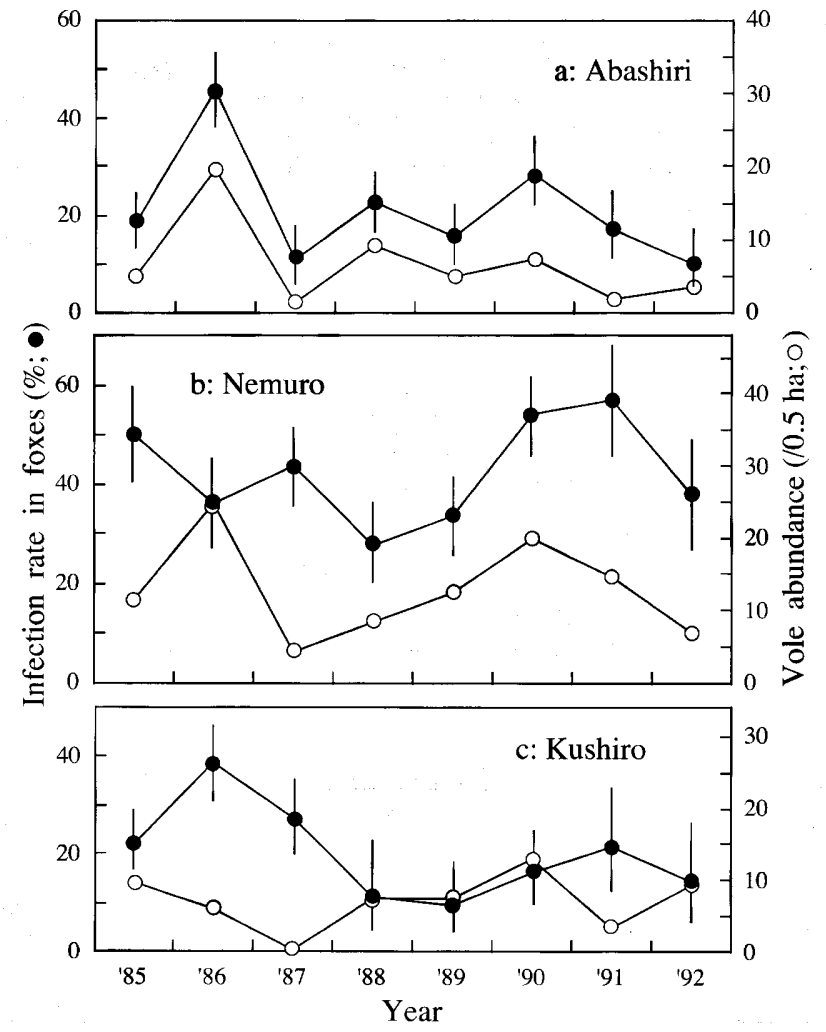

Fig. 4. Changes in the infection rate of E. multilocularis in red foxes, and in abundance of gray-sided voles in (a) Abashiri district, (b) Kushiro district, and (c) Nemuro area. Error bars are $95 \%$ confidence intervals. average rates (SE) were similar, 21.1\% (4.12) in Abashiri and $20.2 \%$ (3.34) in Kushiro. Infection rates in Nemuro were relatively stable in comparison and significantly higher than in the other two districts (Fig. 4b; Permutation test, $P=0.023$ for Abashiri, $P=0.016$ for Kushiro). The average rate in Nemuro $(44.7 \%$; $\mathrm{SE}=3.88)$ was more than twice as high as in the other districts. Amplitude, which was indicated by the average difference between the highest and lowest infection rate within three years on log-10 scale, was 0.20 in Nemuro, 0.42 in Abashiri and 0.32 in Kushiro.

\section{Vole abundance}

Vole abundance were also significantly higher in Nemuro than in the other two districts (Permutation test, $P=0.016$ for Abashiri, $P=0.031$ for Kushiro; Fig. 4). The average abundance (i.e. the number of captured voles per 150 trap-nights; $0.5 \mathrm{ha}$ ) in Nemuro (14.6; $\mathrm{SE}=2.71$ ) was more than twice as high as that in Abashiri (6.0; $\mathrm{SE}=1.94)$ and in Kushiro (6.7; $\mathrm{SE}=1.29$ ). Although vole populations appeared to fluctuate more greatly in Abashiri and Nemuro than in Kushiro, the amplitude in Nemuro (0.48) was smaller than in Abashiri (0.83) and in Kushiro (0.81).

\section{Relationship between fox infection and vole abundance}

The infection rate in foxes and vole abundance fluctuated synchronously in Abashiri (Fig. 4a). There, at least, it cannot be doubted that the infection rate in foxes depends directly on vole abundance. In Nemuro the infection rate seemed to track the vole abundance with one-year lag (Fig. 4b). In Kushiro infection rates in foxes showed similar (but less clear) patterns to those in Nemuro (Fig. 4c).

The relationship between infection rate in foxes and vole abundance was analyzed by the logistic regression (Table 2). When the data in three districts were combined, the significant interaction was found between region and infection rates in foxes in year $t-1\left(r_{t-1}\right)$ and the significance of the interaction between region and the current-year abundance of voles $\left(N_{t}\right)$ was marginal. This implies that influential variables on infection rates in foxes $\left(r_{t}\right)$ differed among the three regions. Only the currentyear abundance of voles $\left(N_{t}\right)$ was significant in Abashiri. Voles abundance in both the current year $\left(N_{t}\right)$ and previous year $\left(N_{t-1}\right)$ were significant in Nemuro. All three variables were significant in Kushiro. Although a significant correlation was detected between infection rates in foxes in year $t-1\left(r_{t-1}\right)$ and vole densities in year $t-1$ $\left(N_{t-1}\right)$ in Abashiri (Kendall's test, $t=0.810, P=0.011$ ), this correlation did not affect the results of the regression analysis. No other correlations were found between indicators. 
Table 2. Summary of results of logistic regression analyses. The occurrence of infected foxes per year was regressed on three indicator variables: the infection rates in foxes in year $t-1\left(r_{t-1}\right)$; vole abundance in year $t\left(N_{t}\right)$, and vole abundance in year $t-1\left(N_{t-1}\right)$. Regression coefficients $(\beta)$, standard error (SE) of the coefficients, test statistic (the Wald statistic), partial correlation $(R)$, and the odds of an event occurring $(\operatorname{Exp}(\beta))$ are given for each variable. Interaction between region and variables was analyzed combining the data in the three regions. ${ }^{* * *} P<0.001$.

\begin{tabular}{|c|c|c|c|c|c|}
\hline $\begin{array}{l}\text { Whole data } \\
\text { Pearson Chi square }=21.203 \\
\text { Log likelihood }=-1405.6\end{array}$ & & & $\mathrm{df}=9$ & & \\
\hline Indicator variables & $\beta$ & $\mathrm{SE}$ & Wald & $R^{\mathrm{a}}$ & $\operatorname{Exp}(\beta)$ \\
\hline$r_{t-1}$ & -0.269 & 0.180 & 2.245 & -0.009 & 1.309 \\
\hline$N_{t}$ & 0.434 & 0.125 & $12.000^{* * *}$ & 0.058 & 1.543 \\
\hline$N_{t-1}$ & 0.622 & 0.147 & $17.914^{* * *}$ & 0.074 & 1.863 \\
\hline Intercept & & & & & \\
\hline Abashiri & -2.821 & & & & \\
\hline Kushiro & -1.160 & & & & \\
\hline Nemuro & -2.950 & & & & \\
\hline \multicolumn{6}{|c|}{ Interaction between the region and variables } \\
\hline$r_{t-1} \times$ region & Chi square $=24.887^{* * *}$ & & & $\mathrm{df}=\mathbf{2}$ & \\
\hline$N_{t} \times$ region & Chi square $=5.970$ & & & $\mathrm{~d} \mathbf{f}=\mathbf{2}$ & \\
\hline$N_{t-1} \times$ region & Chi square $=3.616$ & & & $\mathrm{~d} \mathbf{f}=\mathbf{2}$ & \\
\hline \multicolumn{6}{|l|}{ Abashiri } \\
\hline Pearson Chi square $=9.386$ & & & $\mathrm{df}=3$ & & \\
\hline Log likelihood $=-496.4$ & & & & & \\
\hline Indicator variables & $\beta$ & SE & Wald & $R^{\mathrm{a}}$ & $\operatorname{Exp}(\beta)$ \\
\hline$r_{t-1}$ & 0.204 & 0.473 & 0.186 & 0.000 & 1.226 \\
\hline$N_{t}$ & 0.886 & 0.142 & $38.731^{* * *}$ & 0.186 & 2.425 \\
\hline$N_{t-1}$ & 0.173 & 0.261 & 0.440 & 0.000 & 1.189 \\
\hline Intercept & -2.816 & & & & \\
\hline \multicolumn{6}{|l|}{ Kushiro } \\
\hline Pearson Chi square $=4.483$ & & & $\mathrm{df}=\mathbf{3}$ & & \\
\hline \multicolumn{6}{|l|}{ Log likelihood $=-337.9$} \\
\hline Indicator variables & $\beta$ & S.E. & Wald & $R^{\mathrm{a}}$ & $\operatorname{Exp}(\beta)$ \\
\hline$r_{t-1}$ & 1.616 & 0.341 & $22.456^{* * *}$ & 0.169 & 5.031 \\
\hline$N_{t}$ & 0.529 & 0.154 & $11.801^{* * *}$ & 0.117 & 1.697 \\
\hline$N_{t-1}$ & 0.749 & 0.156 & $23.015^{* * *}$ & 0.172 & 2.114 \\
\hline Intercept & -1.160 & & & & \\
\hline \multicolumn{6}{|l|}{ Nemuro } \\
\hline Pearson Chi square $=\mathbf{7 . 3 3}$ & & & $\mathrm{df}=\mathbf{3}$ & & \\
\hline Log likelihood $=-571.2$ & & & & & \\
\hline Indicator variables & $\beta$ & S.E. & Wald & $R^{\mathrm{a}}$ & $\operatorname{Exp}(\beta)$ \\
\hline$r_{t-1}$ & -.2689 & 0.180 & 2.244 & -0.015 & 0.764 \\
\hline$N_{t}$ & 0.434 & 0.125 & $11.994^{* * *}$ & 0.092 & 1.544 \\
\hline$N_{t-1}$ & 0.622 & 0.147 & $17.909^{* * *}$ & 0.117 & 1.863 \\
\hline Intercept & -2.950 & & & & \\
\hline
\end{tabular}

${ }^{a} R$ is defined as follows:

$R= \pm \sqrt{\frac{W-2 K}{-2 L L_{(0)}}}$

where $W$ is the Wald statistic, $K$ is the degrees of freedom for the variable, and $L L_{(0)}$ is the $\log$ likelihood of a base model. 


\section{Discussion}

Abundance of gray-sided voles directly affected infection rates of E. multilocularis in red foxes in the three study regions, particularly in Abashiri (Fig. 4). The infection rates in foxes in Nemuro and in Kushiro were also significantly influenced by vole abundance in the previous year (Table 2).

The effects of vole abundance in the current year $\left(N_{t}\right)$ may derive from the functional response of foxes to vole abundance, while several candidates could be listed for causes of the delayed effect of vole abundance; e.g. the numerical response of foxes to the vole abundance, the interactive relationship between fox and voles.

The red fox is an opportunistic predator feeding mainly on small rodents (Lloyd 1980); such general food habits are also observed in Hokkaido (Abe 1975; Misawa 1979; Yoneda 1979, 1982; Kondo et al. 1986). As vole densities increase, red foxes eat more voles (Abe 1975; Yoneda 1983; Giraudoux 1991; Ferrari and Weber 1995). Direct density-dependence of infection rates in foxes on vole densities is therefore reasonable, because the more voles a red fox eats, the more likely the fox is to be infected. Haukisalmi and Henttonen (1994) reported the high frequency of bank voles (C. glareolus) infected by tapeworms (Taenia polyacantha) at high-density prey patches, at which foxes foraged intensively.

In both Nemuro and Kushiro, infection rate $\left(r_{t}\right)$ was significantly influenced by the prior-year vole abundance $\left(N_{t-1}\right)$ in addition to those in the current year $\left(N_{t}\right.$; Table 2$)$.

Fox food habits are determined by food availability. For instance heavy snow or grass cover deters foxes from hunting voles (Yoneda 1983; Lindström and Hörnfeldt 1994). In Abashiri the proportion of voles in the diet of red foxes decreases from $20-40 \%$ in fall to $5-10 \%$ in winter (Yoneda 1982), whereas the proportion is still high (43-56\%) in winter in Kushiro and in Nemuro (Abe 1975; Kondo et al. 1986), probably because of less snow (Table 1). Regional differences in winter food habits of foxes should influence the overwintering process of the parasite. In Nemuro and Kushiro the infection cycle may be maintained even in winter, since foxes continue to eat voles, whereas in Abashiri the infection cycle may be interrupted in winter, when the proportion of voles in the fox's diet becomes extremely low. The infection rate in Abashiri should thus be less influenced by the state of the prior-year prevalence. In contrast, in Nemuro and Kushiro, the relationship may carry over from year to year.

Although red fox populations may respond to vole densities through other process for delayed density-dependence, i.e. numerical response, there are unfortunately no reliable data on population dynamics of the red fox in Hokkaido. In Fennoscandia, however, several fluctua- tion patterns in red fox populations have been observed in connection with vole densities. Populations of foxes track vole populations (Hörnfeldt et al. 1986; Lindén 1988; Lindström 1989; Small et al. 1993); fox populations exhibit cyclic fluctuations in the north where fewer alternative prey are present, whereas it is more stable in the south where the diet is more diverse (Englund 1970; Angelstam et al. 1984, 1985). Hokkaido has a rich alternative prey community (hares, grouse, and frogs) like southern Fennoscandia (Henttonen et al. 1992), though some vole populations in Hokkaido are cyclic as well as those in the north of Fennoscandia (Bjørnstad et al. 1996, 1998; Stenseth et al. 1996; Saitoh et al. 1998b). Fox populations therefore would not respond numerically to vole populations in Hokkaido.

The regression results in Nemuro and Kushiro were similar, except that the prior-year fox infection rate, which was significant in Kushiro, was not significant in Nemuro (Table 2). Infection rates in foxes in Nemuro were always high. Fluctuations in the infection rate at a high level would hardly affect subsequent prevalence, if there is the upper limit in its effects.

The present analyses may be too simplistic to elucidate the mechanisms of prevalence of E. multilocularis with alternating hosts. We ignored seasonal changes in infection rates both in red foxes and in voles. The transferring process of eggs from fox feces to ingestion by a vole is still unknown in the field. Abundance of the final hosts (foxes), the degree to which the parasite induces host disadvantage, and immunity are also not known. Thus, it is very difficult to discuss the present results in context with a general model explaining parasitic infection (e.g. Anderson and May 1979; May and Anderson 1979). Nevertheless several interesting facts could be detected. Different responses of infection rates in foxes to vole abundance between Abashiri (direct density-dependence), and Nemuro and Kushiro (direct and delayed density-dependence) should be noticed among them. As a plausible explanation we discussed the functional responses of foxes to vole densities and the overwintering process of the parasite.

The regionally contrasted results for the relationship between infection rate in foxes and vole abundance are parallel to the regional difference in fluctuation pattern of vole populations in Hokkaido. Vole populations in Abashiri area are highly variable and cyclic, whereas those in Kushiro-Nemuro area are less variable and less cyclic (Bjørnstad et al. 1998; Saitoh et al. 1998b). Drastic change in populations of this keystone species may essentially affect the host-parasite system.

This study demonstrates the tight relationship between voles and foxes through the parasite E. multilocularis in the field. The regional differences suggest that the host-parasite relationship is variable. Species and population fluctuation patterns of a main intermediate 
host of this parasite differ among regions; e.g. Microtus species are more important than Clethrionomys species in central Europe and central North America, though the red fox is the main final host in these regions (Raush 1995). Thus comparative studies among different ecological systems must be warranted. Field studies, which measure other parameters than ones reported here, are also required to hypothesize for the mechanism of the host-parasite system. Although we suggest that the functional responses of foxes to vole densities and the overwintering process of the parasite may be essential for the host-parasite system, mechanistic explanation in this multiple species system is still speculative. We hope that further empirical and theoretical work are stimulated by this study.

Acknowledgements: We are indebted to the Department of Health and Welfare of the Hokkaido government for their cooperative investigation of red foxes. We are also indebted to the Department of Forestry, Hokkaido government, and to the Forestry Agency of the Japanese Government for providing the census data on vole populations. We appreciate Keisuke Nakata for his kind advice on data arrangement. Patrick Giraudoux, Kohji Uraguchi, Norio Yamamura, Hirofumi Hirakawa, Voitto Haukisalmi, and Nils Chr. Stenseth made valuable comments on an earlier version of the manuscript. In addition to commenting on an earlier version of this paper, Ottar $\mathrm{N}$. Bjørnstad, Nigel G. Yoccoz and Kenichi Ozaki gave us kind advice on statistical analyses.

\section{References}

Abe, H. (1975) Winter food of the red fox, Vulpes vulpes schrencki Kishida (Carnivora: Canidae), in Hokkaido, with special reference to vole populations. Applied Entomology and Zoology 10: 40-51.

Anderson, R. M. and R. M. May (1979) Population biology of infectious diseases: part I. Nature 280: 361-367.

Angelstam, P., E. Lindström and P. Widén (1984) Role of predation in short-term population fluctuations of some birds and mammals in Fennoscandia. Oecologia 62: 199-208.

Angelstam, P., E. Lindström and P. Widén (1985) Synchronous short-term population fluctuations of some birds and mammals in Fennoscandia - occurrence and distribution. Holarctic Ecology 8: $285-298$.

Bjørnstad, O. N., S. Champely, N. C. Stenseth and T. Saitoh (1996) Cyclicity and stability of grey-sided voles, Clethrionomys rufocanus, of Hokkaido: spectral and principal components analyses. Philosophical Transactions of the Royal Society of London B 351: 867-875.

Bjørnstad, O. N., N. C. Stenseth, T. Saitoh and O. C. Lingjærde (1998) Mapping the regional transition to cyclicity in Clethrionomys rufocanus: spectral densities and functional data analysis. Researches on Population Ecology 40: 77-84.

Englund, J. (1970) Some aspects of reproduction and mortality rates in Swedish foxes (Vulpes vulpes) 1961-63 and 1966-69. Viltrevy 8: 1-82.

Ferrari, N. and J.M. Weber (1995) Influence of the abundance of food resources on the feeding habits of the red fox, Vulpes vulpes, in western Switzerland. Journal of Zoology, London 236: 117-
129.

Giraudoux, P. (1991) Utilisation de l'espace par les hôtes du tenia Multiloculaire (Echinococcus multilocularis): conséquences épidémiologiques. Ph. D. thesis, Université de Bourgogne (in French).

Haukisalmi, V. and H. Henttonen (1990) The impact of climatic factors and host density of the long-term population dynamics of vole helminths. Oecologia 83: 309-315.

Haukisalmi, V. and H. Henttonen (1994) Population dynamics of Taenia polyacantha metacestodes in the bank vole Clethrionomys glareolus. Annales Zoologici Fennici 30: 81-84.

Henttonen, H., L. Hansson and T. Saitoh (1992) Rodent dynamics and community structure: Clethrionomys rufocanus in northern Fennoscandia and Hokkaido. Annales Zoologici Fennici 29: 1-6.

Hörnfeldt, B., O. Löfgren and B-G. Carlsson (1986) Cycles in voles and small game in relation to variations in plant production indices in Northern Sweden. Oecologia 68: 496-512.

Ishige, M., T. Ito and K. Yagi (1993) Temperature effects on life span of Echinococcus multilocularis eggs. Report of Hokkaido Institute of Public Health 43: 49-51 (in Japanese).

Kaneko, Y., K. Nakata, T. Saitoh, N. C. Stenseth and O. N. Bjørnstad (1998) The biology of the vole Clethrionomys rufocanus: a review. Researches on Population Ecology 40: 21-37.

Kondo, N., K. Takahashi and K. Yagi (1986) Winter food of the red fox, Vulpes vulpes schrencki Kishida, in the endemic area of multilocular echinococcosis. The Bulletin of Preparative Office of Nemuro Municipal Museum 1: 23-31 (in Japanese with English summary).

Korpimäki, E. (1993) Regulation of multiannual vole cycles by density-dependent avian and mammalian predation? Oikos 66: 359362.

Korpimäki, E. (1994) Rapid or delayed tracking of multi-annual vole cycles by avian predators? Journal of Animal Ecology 63: 619-628.

Korpimäki, E. and K. Norrdahl (1991) Numerical and functional responses of kestrels, short-eared owls and long-eared owls to vole densities. Ecology 72: 814-826.

Korpimäki, E., K. Norrdahl and T. Rinta-Jaskari (1991) Responses of stoats and least weasels to fluctuating food abundances: is the low phase of the vole cycle due to mustelid predation? Oecologia 88: $552-561$.

Lindén, H. (1988) Latitudinal gradients in predator-prey interactions, cyclicity and synchronism in voles and small game populations in Finland. Oikos 52: 341-349.

Lindström, E. R. (1989) Food limitation and social regulation in a red fox population. Holarctic Ecology 12: 70-79.

Lindström, E. R. (1992) Diet and demographics of the red fox (Vulpes vulpes) in relation to population density - The sarcoptic mange event in Scandinavia. pp. 922-931. In D. R. McCullough and R. H. Barrett (eds.) Wildlife 2001: populations. Elsevier Applied Science, London.

Lindström, E. R. (1994) Large prey for small cubs - on crucial resources of a boreal red fox population. Ecography 12: 70-79.

Lindström, E. R. and B. Hörnfeldt (1994) Vole cycles, snow depth and fox predation. Oikos 70:156-160.

Lloyd, H. G. (1980) The red fox. B. T. Batsford LTD, London.

May, R. M. and R. M. Anderson (1979) Population biology of infectious diseases: part II. Nature 280: 455-461.

Misawa, E. (1979) Change in the food habits of the red fox, Vulpes vulpes schrencki Kishida according to habitat conditions. Journal of the Mammalogical Society of Japan 7: 311-320 (in Japanese with English summary).

Ohbayashi, M. (1996) Host of Echinococcus multilocularis in 
Hokkaido. pp. 59-64. In J. Uchino and N. Sato (eds.) Alveolar Echinococcosis: strategy for eradication of alveolar echinococcosis of the liver. Fujishoin, Sapporo.

Ota, K. (ed.) (1984) Study on wild murid rodents in Hokkaido. Hokkaido University Press, Sapporo (in Japanese).

Rausch, R. L. (1995) Life cycle patterns and geographic distribution of Echinococcus species. pp. 89-134. In R. C. A. Thompson and A. J. Lymbery (eds.) Echinococcus and hydatid disease. CAB International, Wallingford, Oxon.

Rohner, C. (1997) The numerical response of great horned owls to the snowshoe hare cycle: consequences of non-territorial 'floaters' on demography. Journal of Animal Ecology 65: 359-370.

Saitoh, T. (1987) A time series and geographical analysis of population dynamics of the red-backed vole in Hokkaido, Japan. Oecologia 73: 382-388.

Saitoh, T., N. C. Stenseth and O. N. Bjørnstad (1997) Density dependence in fluctuating grey-sided vole populations. Journal of Animal Ecology 66: 14-24.

Saitoh, T., O. N. Bjørnstad and N. C. Stenseth (1998a) Densitydependence in voles and mice: a comparative study. Ecology (in press).

Saitoh, T., N. C. Stenseth and O. N. Bjørnstad (1998b) The population dynamics of the vole Clethrionomys rufocanus in Hokkaido, Japan. Researches on Population Ecology 40: 61-76.

Sapporo District Meteorological Office (1991-1992) The climate in Hokkaido. Nihon Kisho-kyokai, Sapporo (in Japanese).

Schantz, P. M., J. Chai, P. S. Craig, J. Eckert, D. J. Jenkins, C. N. L. Macpherson and A. Thakur (1995) Epidemiology and control of hydatid disease. pp. 233-331. In R. C. A. Thompson and A. J. Lymbery (eds.) Echinococcus and hydatid disease. CAB International, Wallingford, Oxon.

Siegel, S. and N. J. Castellan, Jr. (1988) Nonparametric statistics for the behavioral sciences. McGraHill Book Company, New York.
Small, R. J., V. Marcstrom and T. Willebrand (1993) Synchronous and nonsynchronous population fluctuations of some predators and their prey in central Sweden. Ecography 16: 360-364.

Stenseth, N. C., O. N. Bjørnstad and T. Saitoh (1996) A gradient from stable to cyclic populations of Clethrionomys rufocanus in Hokkaido, Japan. Proceedings of the Royal Society of London B 263: $1117-1126$

Suzuki, K., N. Sato and J. Uchino (1993) I. Epidemiology. pp. 1-9. In J. Uchino and N. Sato (eds.) Alveolar Echinococcosis of the liver. Kokoku Printing, Sapporo.

Veit, P., B. Bilber, V. Schad, J. Schafer, W. Frank and R. Lucius (1995) Influence of environmental factors on the infectivity of Echinococcus multilocularis eggs. Parasitology 110: 79-86.

Yagi, K. and T. Ito (1994) An experimental study of Echinococcus multilocularis in red foxes. Proceedings of the 117th Congress of Japanese Society of Veterinary Science, 132.

Yagi, K., T. Ito and M. Ishige (1996) A survival strategy of Echinococcus multilocularis presumed by experimental studies. pp. 59-64. In J. Uchino and N. Sato (eds.) Alveolar Echinococcosis. strategy for eradication of alveolar echinococcosis of the liver. Fujishoin, Sapporo.

Yoneda, M. (1979) Prey preference of the red fox, Vulpes vulpes schrencki Kishida (Carnivora: Canidae) on small rodents. Applied Entomology and Zoology 14: 28-35.

Yoneda, M. (1982) Influence of red fox predation on a local population of small rodents II. food habits of the red fox. Applied Entomology and Zoology 17: 308-318.

Yoneda, M. (1983) Influence of red fox predation on a local population of small rodents III. seasonal changes in predation pressure, prey preference and predation effect. Applied Entomology and Zoology 18: 1-10.

Received 8 December 1997; Accepted 25 May 1998 